\title{
JUURNAL.RU
}

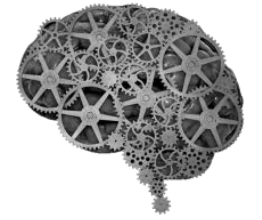

COMPANY GROUP "INTELLEKT"

\author{
Сергеева В.А., Машкова М.С. \\ ГБОУ ВПО «Саратовский ГМУ им. В.И. Разумовского» Минздрава России \\ Саратов, Россия
}

doi: 10.18411/lj2016-5-1-18

\section{Амбулаторная терапия торасемидом у пациентов в зависимости от места жительства}

С появлением в России в 2011 г. нового петлевого диуретика торасемида, показавшего явные преимущества в диуретической терапии, лучший профиль безопасности и наличие плейотропных эффектов по сравнению со своим предшественником фуросемидом, за короткое время сделали этот препарат одним из самых часто назначаемых при ведении пациентов с хронической сердечной недостаточностью (ХCH). Кроме этого, возможность использования торасемида в малых дозах в качестве препарата для плановой терапии артериальной гипертензии (АГ) позволило включить его в арсенал эффективных антигипертензивных средств.

Цель работы: оценить амбулаторную терапию торасемидом у пациентов в зависимости от места жительства.

Материалы и методы: проведено анкетирование 100 пациентов кардиологического профиля нескольких клинических больниц г. Саратова, принимающих диуретические препараты, из которых 86\% имели проявления $\mathrm{XCH,} \mathrm{100 \%} \mathrm{страдали} \mathrm{АГ,} \mathrm{63 \%} \mathrm{-} \mathrm{сахарным} \mathrm{диабетом.} \mathrm{Специально} \mathrm{разработанная}$ анкета содержала вопросы о различных аспектах терапии торасемидом в качестве диуретического либо антигипертензивного препарата. Статистический анализ производился с помощью пакета StatPlus 2009 Professional.

Результаты: средний возраст пациентов (75\% мужчин и $25 \%$ женщин) в 
нашем исследовании составил $64,02 \pm 1,04$ года. $33 \%$ проживало непосредственно в г. Саратов, $42 \%$ опрошенных было из городов Саратовской области, $25 \%$ - из сельской местности. В рамках терапии ХСН препарат принимали 79 \% жителей Саратова, 59 \% жителей городов области и 67 \% жителей СМ. В структуре антигипертензивной терапии принимали торасемид 14 \% пациентов Саратова, 26 \% пациентов городов области и 33 \% пациентов сельской местности. На первом этапе исследования мы оценили, насколько пациенты, имеющие показания к проведению терапии торасемидом, знакомы с этим препаратом. Самый большое число пациентов, принимавших торасемид, оказалось жителями Саратова, 85 \% (из них 76\% продолжают терапию торасемидом и в настоящее время, 9\% - принимали, но бросили прием), пациенты городов области принимали торасемид реже - 64 \% (из которых 45\% проводят терапию торасемидом и в настоящее время, 19\% - отказались от приема препарата). Меньше всех знакомы с торасемидом жители села - лишь 60 \% больных из сельской местности принимали когда-либо торасемид (44\% принимают по настоящее время, 16\% - прекратили прием).

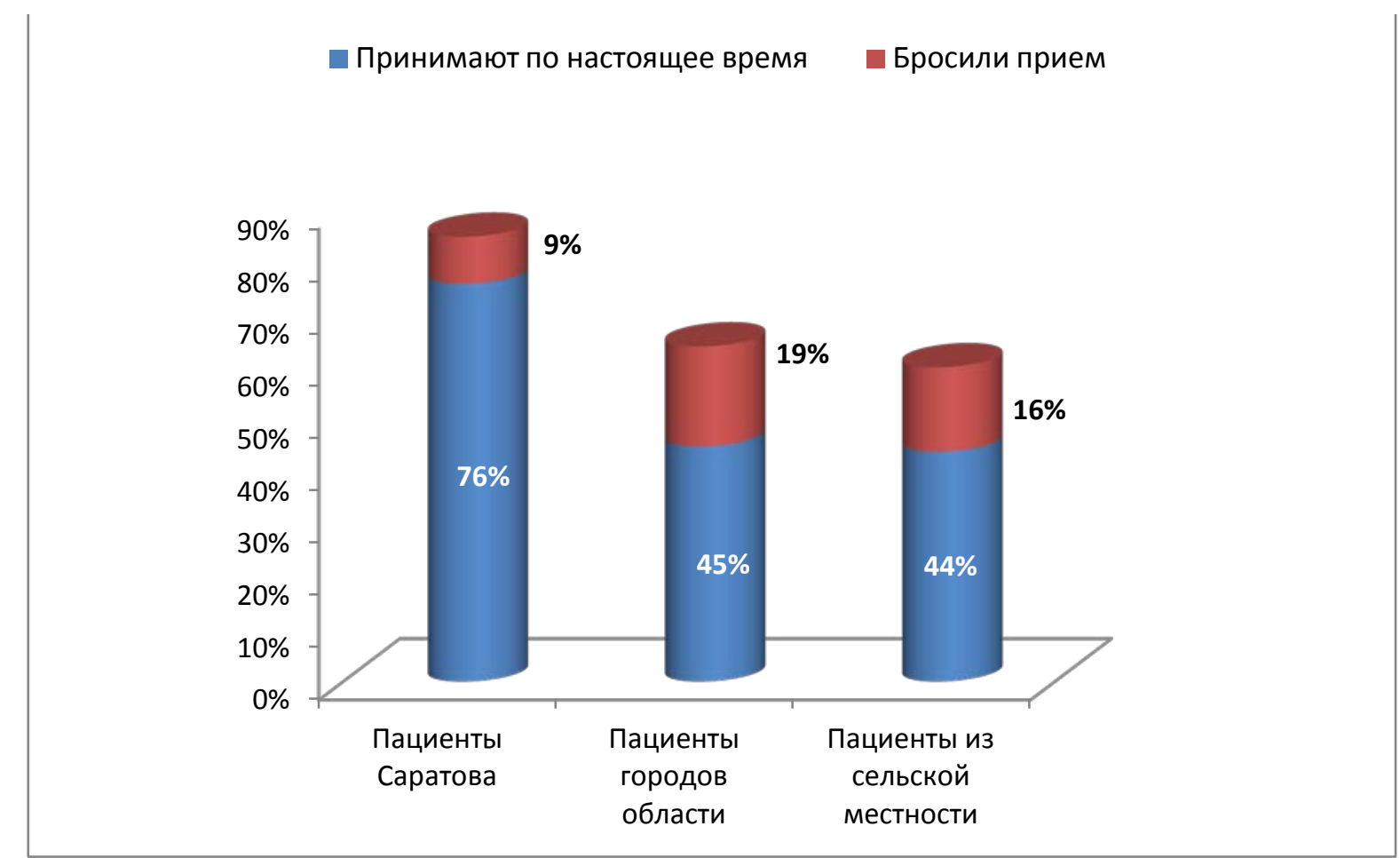

Рис. 1. Режим прима торасемида пациентами в зависимости от места жительства 
Во всех трех группах чаще всего торасемид назначали врачи стационара (рекомендован после выписки на амбулаторный этап): 71 \% - в группе жителей Саратова, 67 \% - в группе из городов области и 93 \% - в группе пациентов из сельской местности. Назначений торасемида врачами амбулаторного звена было меньше: $21 \%$ участковыми терапевтами Саратова, 26 \% участковыми терапевтов городов области и лишь 7 \% сельских участковых терапевтов рекомендовали торасемид своим больным.

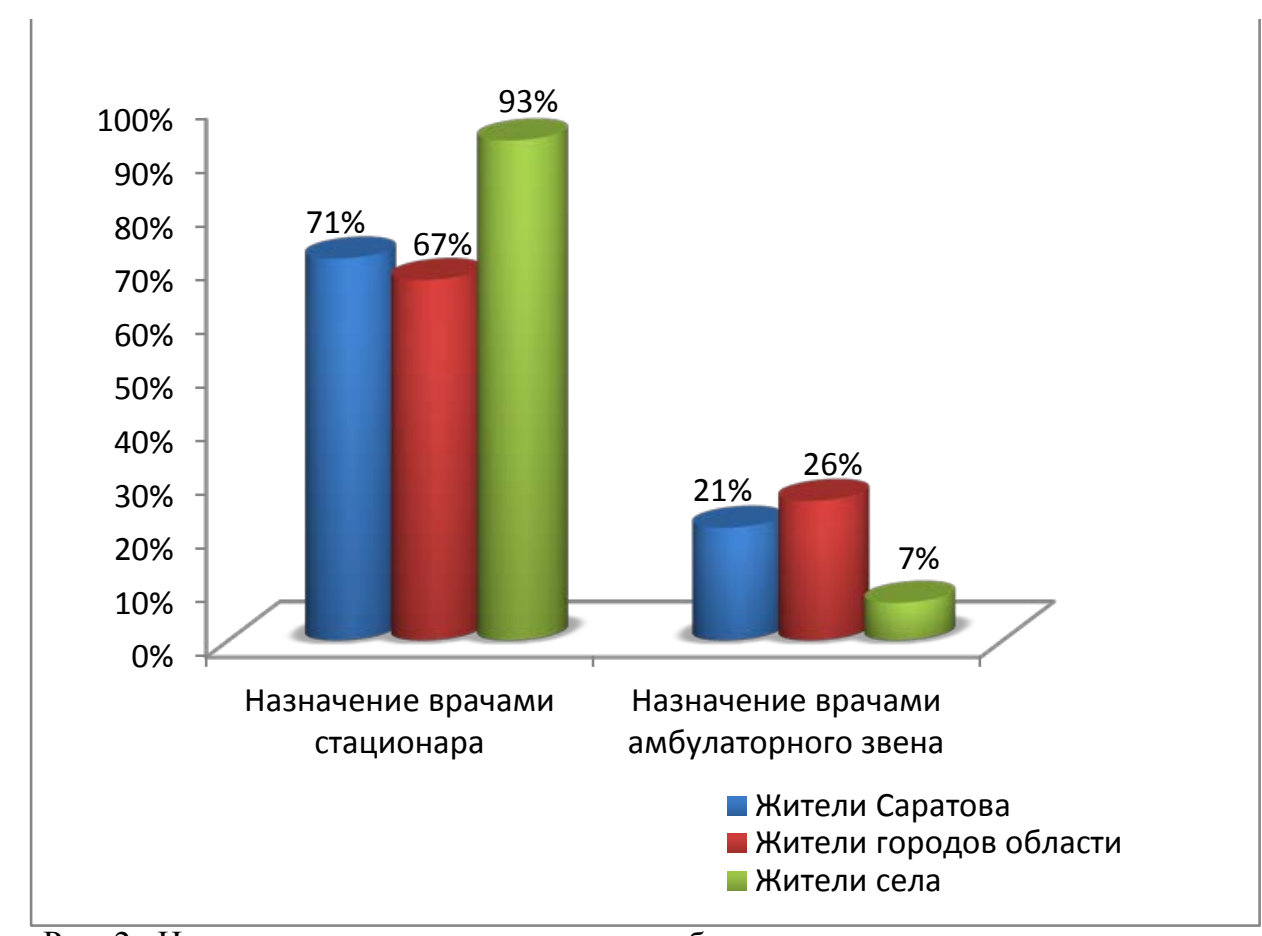

Рис. 2. Назначения торасемида врачами амбулаторного и стационарного звеньев

В отношении режима прима торасемида получено: ежедневно принимали препарат в постоянном режиме - 68\% жителей Саратова, 74\% жителей городов области и 53\% - сельской местности; в режиме - «несколько раз в неделю» 25\% - жителей Саратова, 11\% - жителей городов области, 13\% - жителей сельской местности; в исследовании оказалось также небольшое число пациентов, принимающих препараты торасемида в режиме «несколько раз в месяц» (4\% жителей Саратова, 4\% -жителей городов области и самое большое число таких пациентов - 27\% - из сельской местности). Отказались от приема торасемида $3 \%$ жителей Саратова, по 7\% - городов области и жителей сельской местности. 


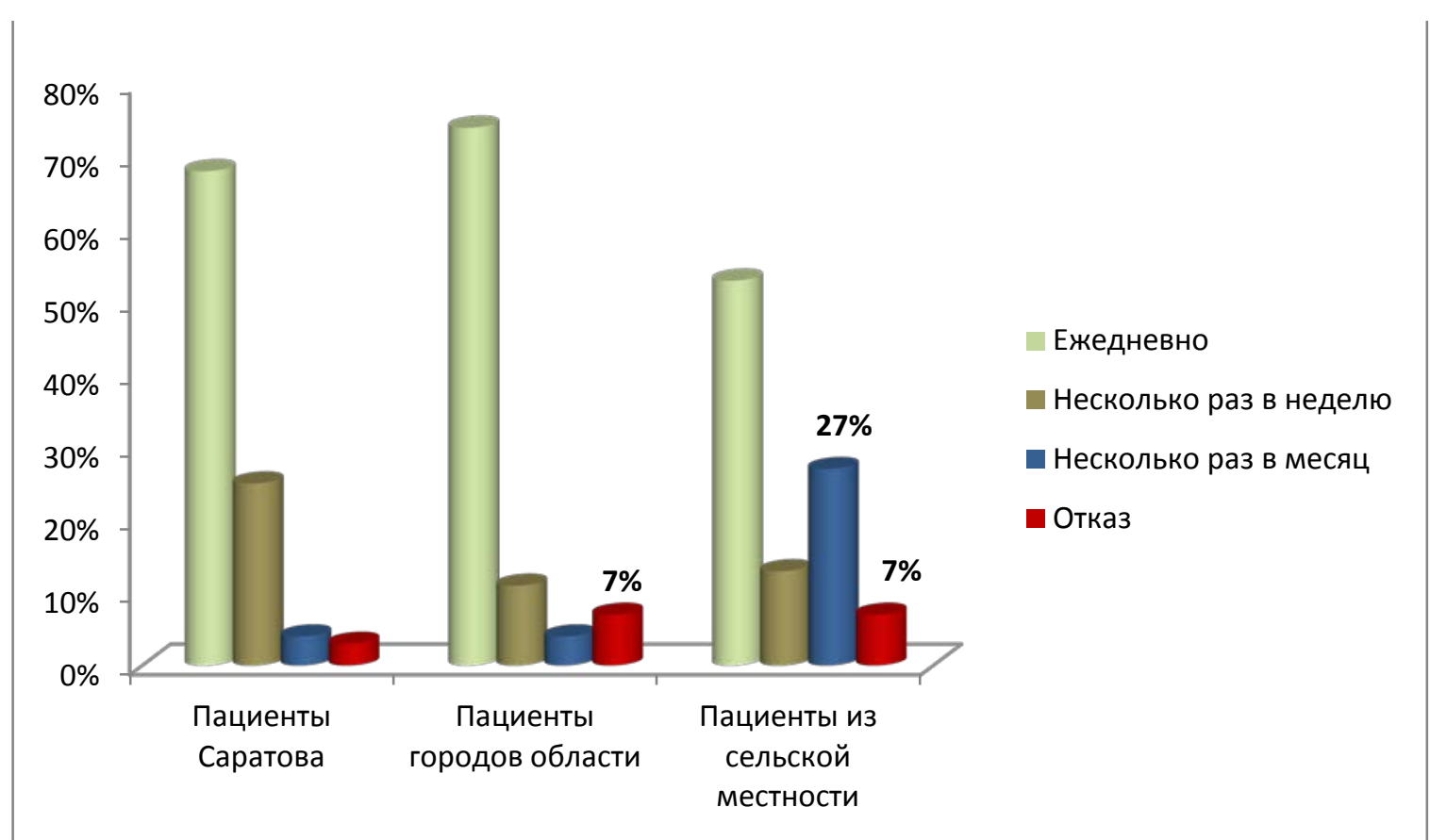

Рис. 3. Режим терапии торасемидом у пациентов в зависимости от места жительства

Средний стаж приёма торасемида у пациентов с постоянным режимом терапии среди жителей Саратова составил $3,18 \pm 0,99$ года, у жителей городов

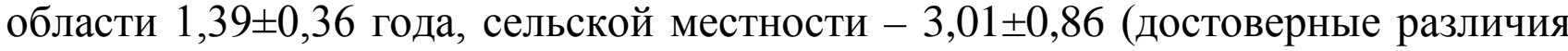
получены между группами пациентов из городов области и сельской местности, p $<0,05)$. Пациентам были заданы вопросы о том, собираются ли они принимать торасемид в дальнейшем, если нет, то в чем причины низкой приверженности терапии. Получено, что среди жителей Саратова $14 \%$ не уверены в том, что будут продолжать лечение препаратом (среди причин возможного отказа от терапии торасемидом 25\% - не считают лечение эффективным, 25\% - плохо переносят терапию, 25\% - по материальным причинам, 25\% - препарат был отменен лечащим врачом); среди жителей городов области $37 \%$ сомневаются в дальнейшем приеме торасемида ( $40 \%$ - считают эффект препарата недостаточным, у 30\% - препарат был отменен лечащим врачом, 20\% - по материальным соображениям, у 10\% - затрудняет повседневную активность); среди жителей сельской местности 33\% сомневаются в продолжении приема торасемида $(40 \%$ - не считают препарат эффективным, по 20\% - плохо переносят, считают дорогостоящим и затрудняет повседневную активность). 
Весьма примечательно, что отмена препарата лечащим врачом также была связана с тем, что лечащий врач считал этот препарат недостаточно эффективным для пациента.

Анализ причин неэффективности препарата показал, что из всех случаев приема торасемида оригинальный препарат (бритомар) получал только 1 человек, в остальных случаях это были генерические препараты разного качества. Кроме этого, дозировка препарата требует коррекции в зависимости от различных клинических ситуаций, выраженности отечного синдрома, индивидуального ответа на препарат и т.д. В нашем исследовании в большинстве случаев (68\% - среди жителей Саратова, 70\% - жителей городов области, 80\% - у сельских жителей) препарат был назначен в стартовой дозе (10 мг) без дальнейшей коррекции и оценки лечащими врачами эффективности такой терапии.

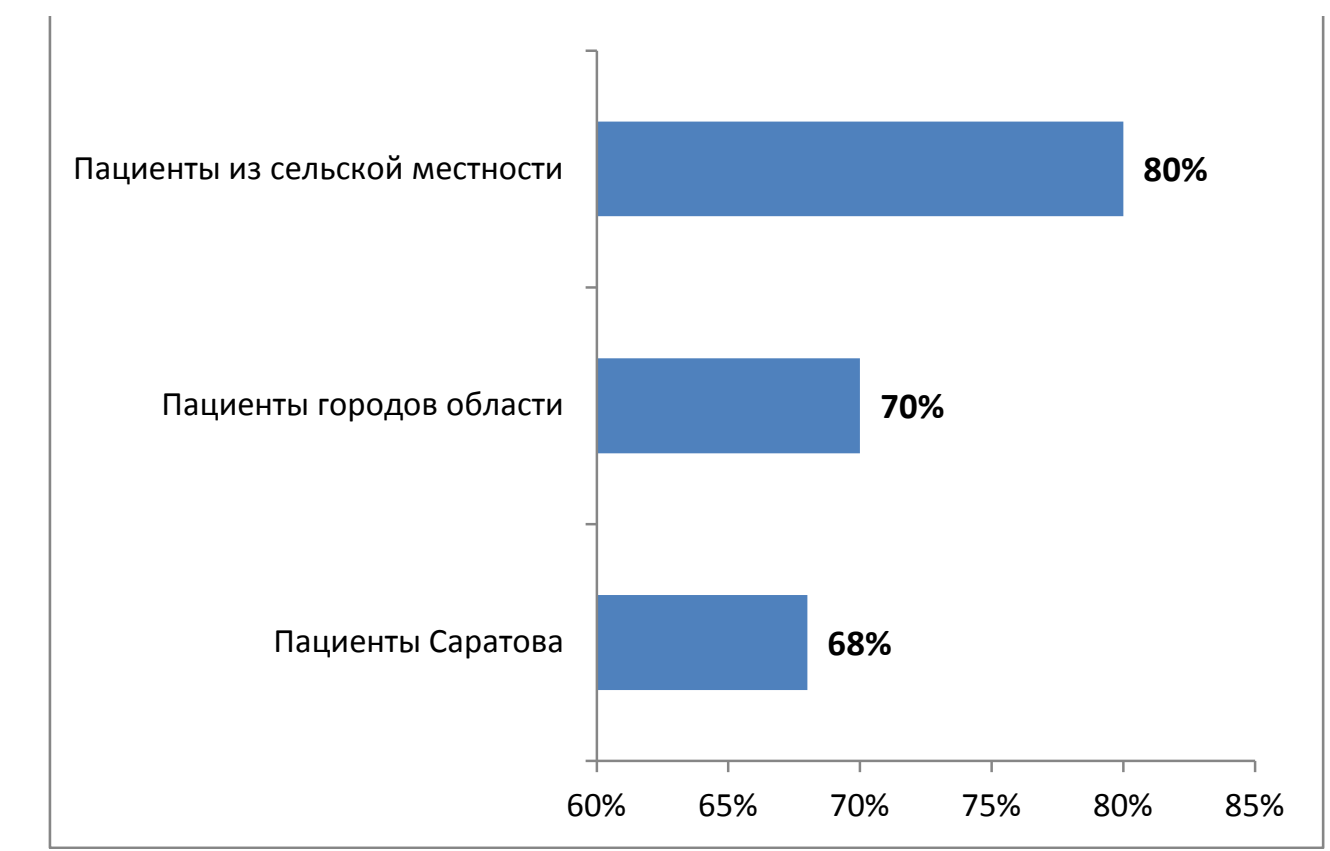

Рис. 4. Отсутствие коррекций дозировки торасемида у пациентов в зависимости от места жительства

Выводы: в целом, терапию торасемидом нельзя назвать адекватной ни в одной группе пациентов. Среди пациентов областного центра и городов области препарат назначается чаще. Незначительное число амбулаторных назначений торасемида и частая отмена его без предварительной коррекции дозы и оценки эффективности свидетельствует о том, что врачи амбулаторного звена 
недостаточно осведомлены обо всех аспектах терапии торасемидом. Недостаточная приверженность терапии торасемидом в большинстве случаев связана с некорректным подбором дозы препарата и преобладанием препаратов - генериков, возможно, не всегда высокого качества. 


\section{Литература}

1. Мареев В. Ю., Агеев Ф. Т., Арутюнов Г. П. и др. Национальные рекомендации ОССН, РКО и РНМОТ по диагностике и лечению ХCH (четвертый пересмотр) // Сердечная недостаточность. 2013. № 7. С. 379472.

2. Кобалава Ж. Д. Пути оптимизации диуретической терапии при застойной хронической сердечной недостаточности - место торасемида пролонгированного высвобождения // Кардиология. 2014. Т. 54. № 4. С. 69-78.

3. Гендлин Г. Е., Рязанцева Е. Е. Роль диуретиков в лечении хронической сердечной недостаточности // Серд. недостаточность. 2012. № 10. С. 23-28.

4. Acuna C. Update: prolonged-release torasemide // Drugs Today (Barc). 2010.- Vol. 46 (Suppl E). - P.1-15.

5. Barbanoja M.J., Ballestera M.R. et al. Comparison of repeated-dose pharmacokinetics of prolonged-release and immediate-release torasemide formulations in healthy young volunteers // Fundamental \& Clinical Pharmacology. - 2009.- Vol. 23. - P. 115-125. 